\title{
Maturity of Skates in Northeast United States Waters
}

\author{
Katherine A. Sosebee \\ National Marine Fisheries Service, NEFSC \\ Woods Hole, MA 02543
}

Sosebee, K. A. 2005. Maturity of Skates in Northeast United States Waters. J. Northw. Atl. Fish. Sci., 35: 141-153. doi:10.2960/J.v35.m499

\begin{abstract}
There are few studies on the life history of most skate species, including the seven resident off the Northeast coast of the United States. Assumptions have been made about longevity, growth rate, and maturity based on body size and relationships developed from a few studied species. In the present study observations on maturity of the seven species of skates in the Northwest Atlantic were made on research surveys during 2000-02. These observations consisted of measurements of body morphometry (clasper length and cloaca length) for which the allometric growth rates change with maturity. A technique primarily used in crustacean biology was employed to estimate the size at first maturity. Values of size at first maturity ranged from $33 \mathrm{~cm}$ for male rosette skate to $105 \mathrm{~cm}$ for female barndoor skate.
\end{abstract}

Key words: life history, skates, maturity, growth, size, morphometry.

\section{Introduction}

The seven species in the skate complex found in the USA Northeast Region (Maine to Virginia) are distributed along the coast of the Northeast United States from the intertidal zone to depths exceeding $700 \mathrm{~m}$ (McEachran, 2002). The species are little skate (Leucoraja erinacea), winter skate (L. ocellata), barndoor skate (Dipturus laevis), thorny skate (Amblyraja radiata), smooth skate (Malacoraja senta), clearnose skate (Raja eglanteria) and rosette skate (L. garmani).

In the Northeast Region, the center of distribution for the little and winter skates is Georges Bank and Southern New England (NEFSC, 2000). The barndoor skate is most common in the Gulf of Maine, on Georges Bank and in Southern New England. Thorny and smooth skates are commonly found in the Gulf of Maine. Clearnose and rosette skates have a more southern distribution, and are found primarily in Southern New England and the Chesapeake Bight. Skates are not known to undertake large-scale migrations (Templeman, 1984), but they do move seasonally in response to changes in water temperature, moving offshore in summer and earlyautumn and returning inshore during winter and spring (McEachran and Musick, 1975).

The life histories of many of these skates are not well known. Some age studies have been accomplished on little, winter, and clearnose skate (Fitz, 1956; Daiber, 1960; Fitz and Daiber, 1963; Johnson, 1979; Waring, 1984; Simon and Frank, MS 1996; Gelsleichter, 1998). Maturity of the thornback ray (Raja clavata) in the northeastern Atlantic was examined using measurements of reproductive organs (clasper length and cloaca length; Steven, 1934). Some studies have used macroscopic determination of maturity to estimate size at 50\% maturity (del Rio and Junquera, MS 2000). Frisk et al. (2001) compiled a summary of available life history parameters for skate species from around the world, and developed predictive relationships between total length $\left(L_{\max }\right)$ and length of maturity $\left(L_{\operatorname{mat}}\right)$ and age of maturity $\left(A_{m a t}\right)$.

In 1999, the National Marine Fisheries Service was petitioned to list barndoor skate as endangered based on a paper by Casey and Myers (1998). A non-lethal method for determining size at first maturity was needed to limit the mortality on barndoor skate. A technique widely used in elasmobranch biology is to examine changes in the allometric growth of reproductive organs to find the length at which the growth changes. Because this method can sometimes be subjective, this study used a statistical technique developed in crustacean biology to find this length.

\section{Materials and Methods}

The seven species of skates were sampled on the Northeast Fisheries Science Center (NEFSC) bottom trawl research surveys and scallop dredge surveys during 2000-02. The trawl surveys are conducted in three seasons: winter (February), spring (March-April) and autumn (September-October) (Azarovitz, 1981). The spring and autumn surveys cover the region from off Cape Hatteras through the Gulf of Maine. The winter survey covers the region from off Cape Hatteras to Georges Bank 
and has a much higher catchability for skates due to the configuration of the gear (NEFSC, 2000). The NEFSC scallop dredge survey is conducted in the summer (JulyAugust). The scallop dredge survey covers the region from Cape Hatteras to Georges Bank but does not cover inshore areas, depths greater than $150 \mathrm{~m}$, or the shallow portions of Georges Bank. Additional samples for some of the species were taken on the Monkfish Cooperative Industry survey in March and April of 2001(NEFSC, 2002). Sampling was conducted on this cooperative survey through the entire Northeast Region with many stations in waters greater than $200 \mathrm{~m}$.

For all skates, measurements of total length (TL, rostrum to tip of tail) were made to the nearest $\mathrm{cm}$. For males, clasper length (CLM) was measured as the length from the posterior portion of the cloacal opening to the tip of the clasper using vernier calipers (Fig. 1). Cloaca length (CLF) was measured in females as the length from the anterior end of the cloacal opening to the anterior end of the cloaca (Fig. 2). This was done by gently inserting the small end of the vernier calipers into the cloaca until it would go no further. Both clasper length and cloaca length measurements were made to the nearest millimeter (mm).

To determine the size at first maturity, the data were examined using a method developed for crustacean maturity (Somerton, 1980). To determine if transformation of the data was needed, CLM or CLF was plotted against TL (Fig. 3). Both variables were log-transformed and the data were then sorted by length. When plotted against each other, an inflection point where two lines having different slopes intersect can be seen (barndoor males, Fig. 5). To determine the point where the two lines meet, it is necessary to run two linear regressions. Beginning with the second data point, the data were split into two subsets, one below that data point (the dataset containing two data points) and the other above (containing the rest of the data). A pair of linear regressions was fit to these subsets of the data and a residual sum of squares calculated. This process was repeated for all the data points, moving the regressions each time (the second pair would have three data points in one regression and one less data point in the second regression). The minimum residual sum of squares occurs at the inflection point which may represent the size at first maturity.

\section{Results}

Barndoor skate were caught mainly in the winter and spring on Georges Bank (Table 1; Fig. 4a). Both the increased catchability of the gear used in the winter survey and the addition of samples from the cooperative survey made these two seasons the basis for the maturity analysis. Winter skate were sampled evenly across seasons (Fig. 4b) and years (Table 1). Clearnose skate were sampled mostly on the winter survey (Table 1; Fig. 4c). No clearnose skate

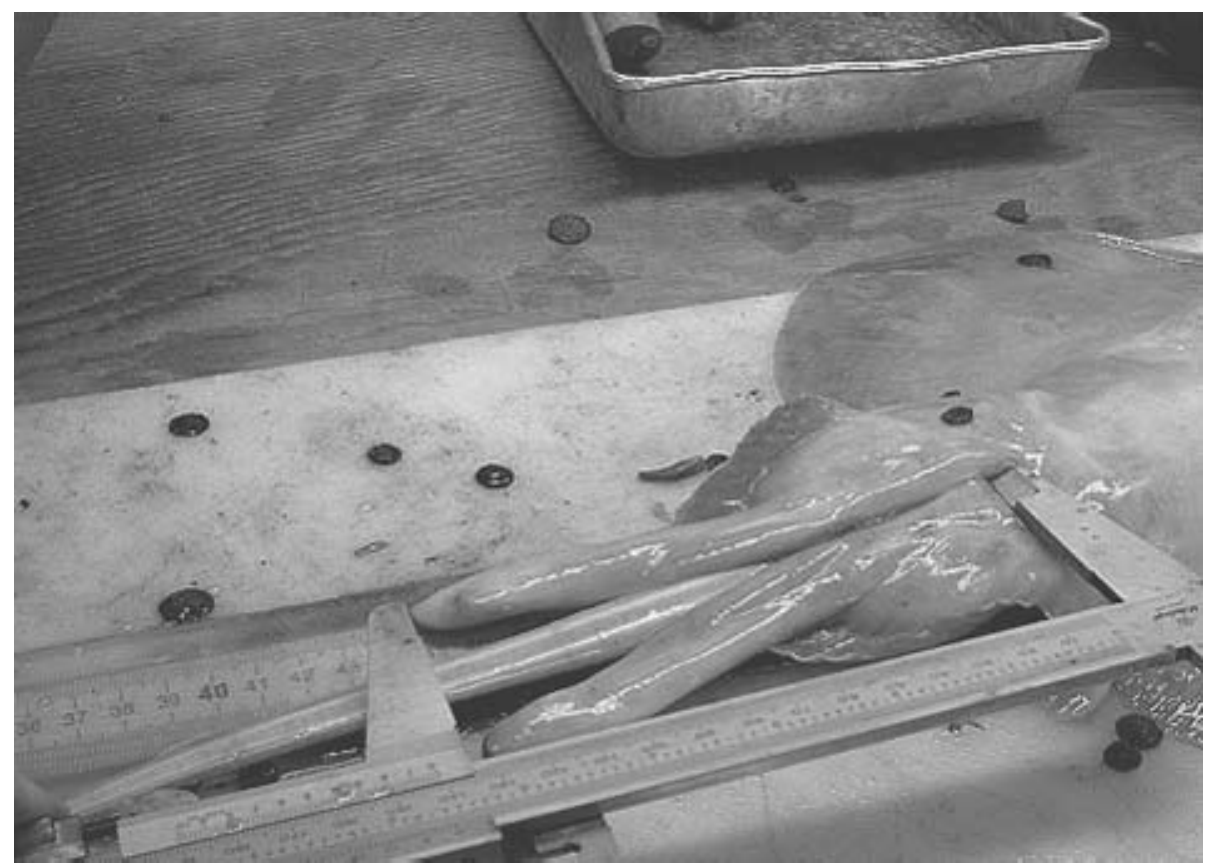

Fig. 1. Method of measurement of clasper length in male skates. 


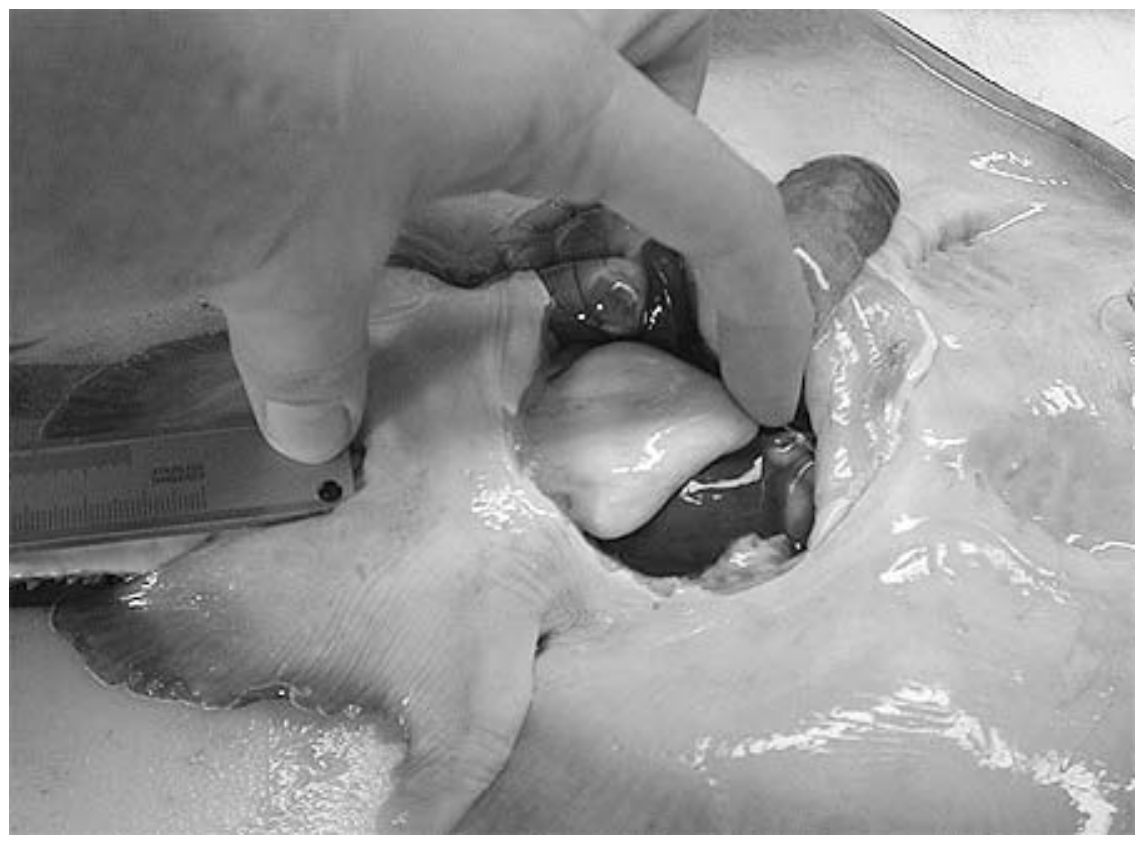

Fig. 2. Method of measurement of cloaca length in female skates.

were caught in the summer on the scallop survey because clearnose skate are generally in inshore waters during the summer and the scallop survey does not cover inshore waters. Rosette skate were sampled during all seasons, but winter was the primary season of capture (Table 1; Fig. 4d). Samples were taken during all seasons for little skate (Table1; Fig. 4e). Smooth and thorny skate were sampled primarily during the spring and autumn because the winter survey does not cover the Gulf of Maine, which is the center of distribution for these two species (Table 1; Fig. $4 \mathrm{f}$ and $4 \mathrm{~g}$ ).

The measurements collected were more consistent for males than for females in all species (Fig. 5a-g). There is a lot more flexibility in measuring the cloaca than in measuring the clasper and this may lead to greater variability in the measurements. An inflection point was evident in the data for the males of each species, but this was less obvious in the data for females because of the greater variability.

The size at first maturity for barndoor skate females ranged from $96 \mathrm{~cm}$ to $105 \mathrm{~cm}$ (Table 2; Fig. 6a). The data for males was less variable and the size was estimated to be $100 \mathrm{~cm}$. (Table 2; Fig. 6a). Winter skate was the only species for which there was a range in the minima of the residual sum of squares for males (Fig. 6b). This gave a range in size at first maturity of $53 \mathrm{~cm}$ to $58 \mathrm{~cm}$ (Table 2). Females began to mature at much larger sizes of $66 \mathrm{~cm}$ to $73 \mathrm{~cm}$ (Table 2; Fig. 6b). Clearnose skate males began to mature at a size of $56 \mathrm{~cm}$ with females maturing at slightly larger sizes of $59 \mathrm{~cm}$ to $65 \mathrm{~cm}$ (Table 2; Fig. 6c). Rosette skate matured at the smallest size, with males maturing at $33 \mathrm{~cm}$ and females at about the same size $(33-35 \mathrm{~cm}$; Table 2; Fig. 6d). Little skate males began maturing at a size of $39 \mathrm{~cm}$ with females maturing at a slightly larger size between 40 and $48 \mathrm{~cm}$ (Table 2: Fig. 6e). Smooth and thorny skate were the two species for which females matured at a smaller size than males (Table 2; Fig. $6 \mathrm{f}$ and $6 \mathrm{~g})$.

\section{Discussion}

Comparison of the sizes at first maturity with those from Frisk et al. (2001) predictive equation cited in NEFSC (2000) reveals that the estimates from this study are generally lower. Since the predictive equation estimates size at $50 \%$ maturity, the lengths from this study should be smaller. The only value that is considerably different is for thorny skate. This may be due to maturation over a large size range that appears to occur in this species. However, a length of $50 \mathrm{~cm}$ agrees well with other estimates from Canadian waters (Templeman, 1982; Simon and Frank, 1996).

The regression technique generally performed better for males than for females in all species. Females generally displayed two possible minima, indicating that maturity may take place over a larger length range than for males or there is much more measurement error. The elasticity of the cloaca also introduced more variability than the 
Females

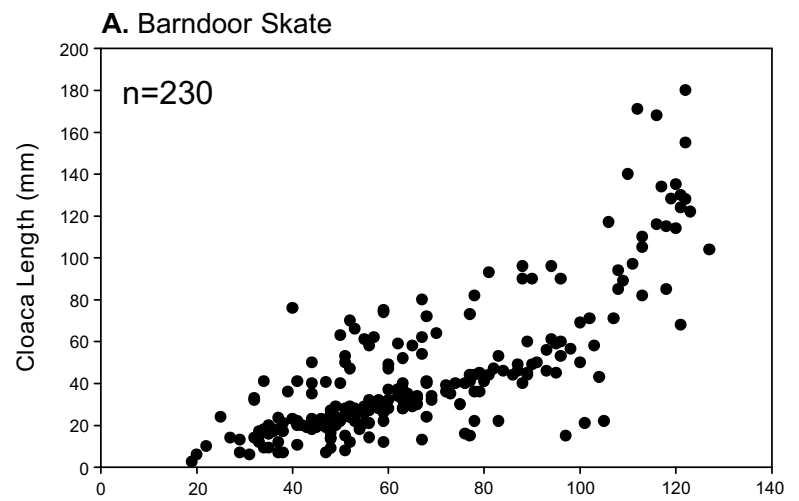

B. Winter Skate

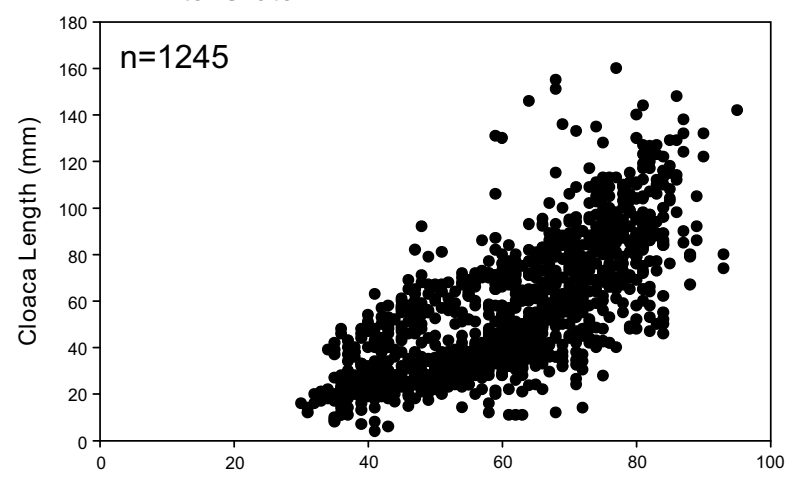

C. Clearnose Skate

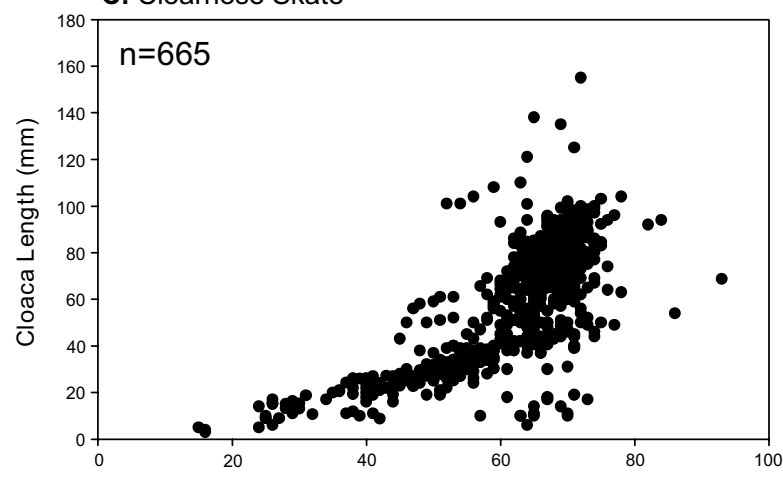

D. Rosette Skate

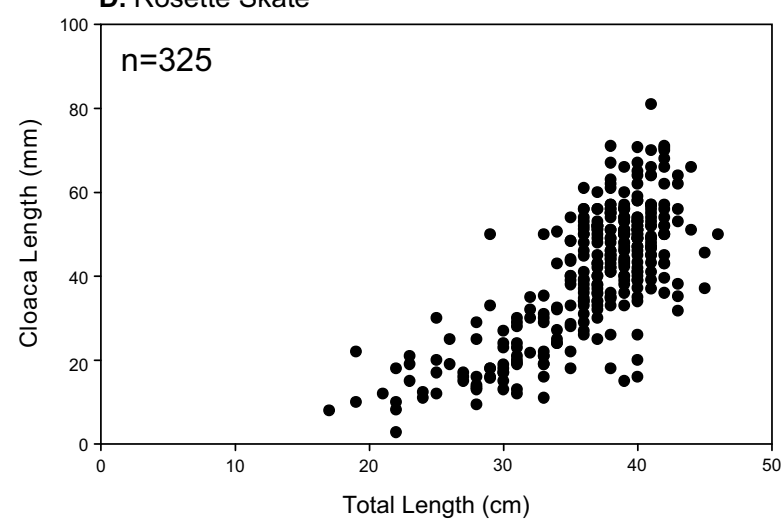

Males
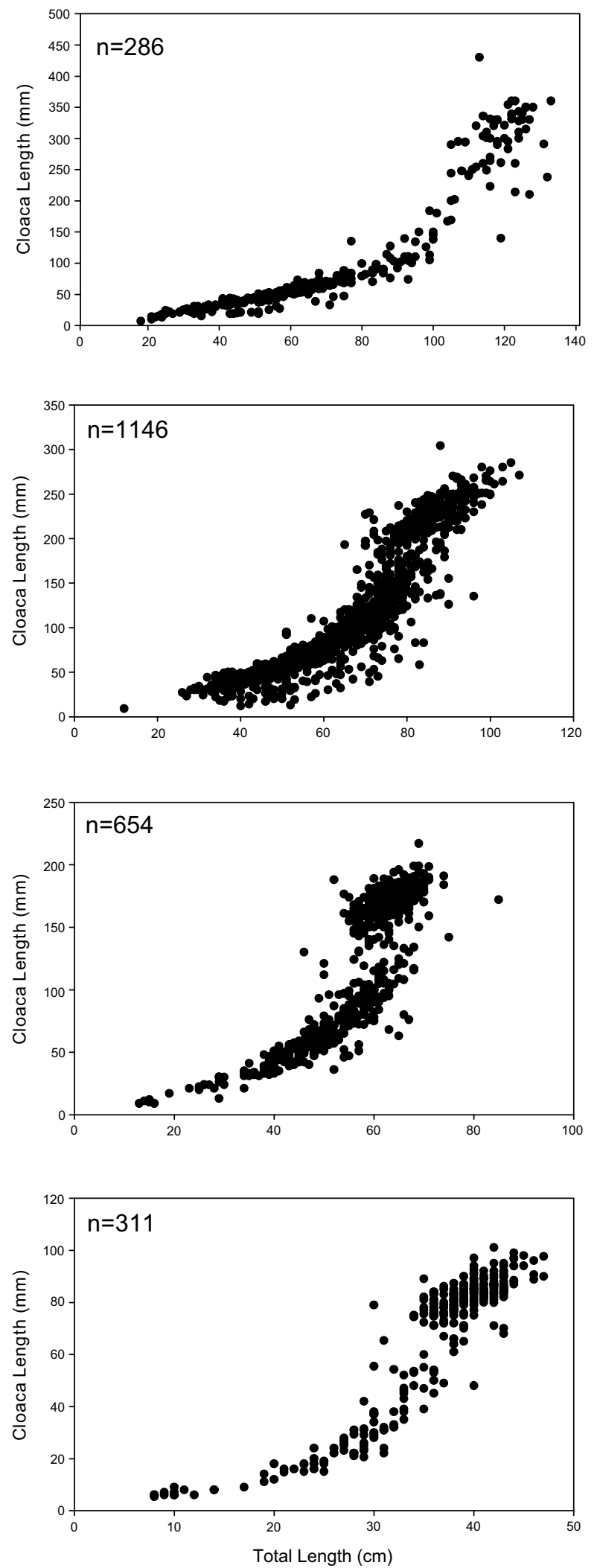

Fig. 3. Clasper length or cloaca length plotted against total length. 

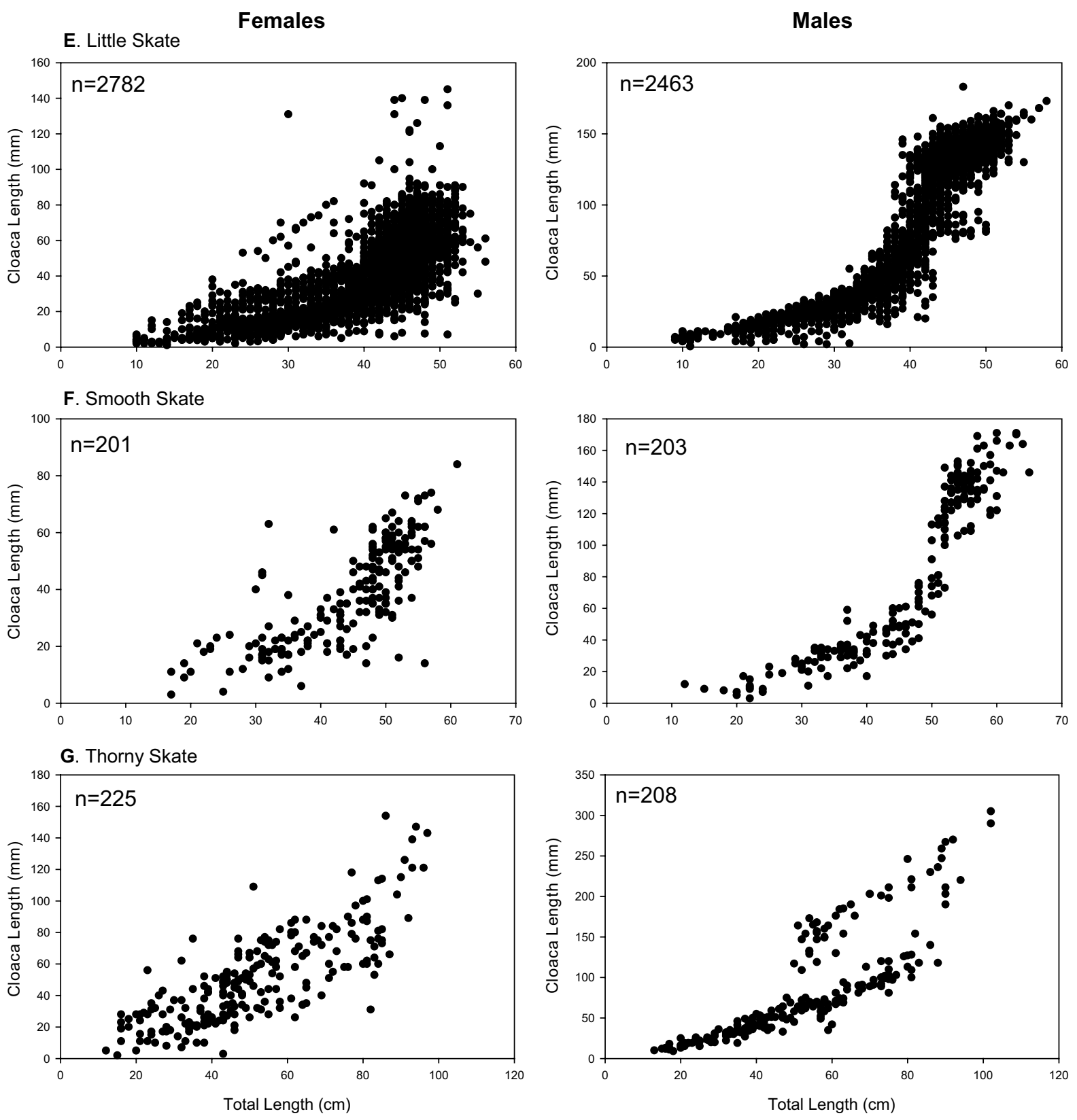

Fig. 3. (Cont'd). Clasper length or cloaca length plotted against total length.

measurement of the clasper. Steven (1934) did not find as much variability in measurements of the cloaca as was found in this study. The blunt tool used by Steven (1934) to measure the cloaca may have provided better measurements compared to the sharp-ended calipers used in the present study that easily penetrated the cloaca.

For some of the species there was also a problem with species identification. In particular, little and winter skate are very easily misidentified. This may have introduced an error where male winter skates seem to mature over a size range rather than at a single size as in most other species. Smooth and thorny have also sometimes been misidentified, particularly at small sizes. This may have contributed to the variance seen in these two species.

The variation seen in female maturation reflects a need for auxiliary information on maturity stages. The regression method may provide some guidance as to the size at first maturity, but using maturity stages based on 
TABLE 1. Number of skates sampled by species, year, sex and season.

\begin{tabular}{|c|c|c|c|c|c|c|c|c|c|c|c|}
\hline & & \multicolumn{2}{|c|}{ Winter } & \multicolumn{2}{|c|}{ Spring } & \multicolumn{2}{|c|}{ Summer } & \multicolumn{2}{|c|}{ Autumn } & \multicolumn{2}{|c|}{ Total } \\
\hline & & $\mathbf{M}$ & $\mathbf{F}$ & M & $\mathbf{F}$ & $\mathbf{M}$ & $\mathbf{F}$ & $\mathbf{M}$ & $\mathbf{F}$ & $\mathbf{M}$ & $\mathbf{F}$ \\
\hline \multirow[t]{4}{*}{ Barndoor } & 2000 & 42 & 22 & 14 & 13 & 8 & 5 & 7 & 8 & 71 & 48 \\
\hline & 2001 & 45 & 36 & 80 & 63 & 14 & 11 & 12 & 21 & 151 & 131 \\
\hline & 2002 & 50 & 40 & 14 & 11 & - & - & - & - & 64 & 51 \\
\hline & Total & 137 & 98 & 108 & 87 & 22 & 16 & 19 & 29 & 286 & 230 \\
\hline \multirow[t]{4}{*}{ Winter } & 2000 & 143 & 89 & 198 & 168 & 82 & 89 & 100 & 132 & 523 & 478 \\
\hline & 2001 & 161 & 140 & 114 & 117 & 75 & 105 & 131 & 186 & 481 & 548 \\
\hline & 2002 & 74 & 89 & 68 & - & 130 & - & - & - & 142 & 219 \\
\hline & Total & 378 & 318 & 380 & 415 & 157 & 194 & 231 & 318 & 1146 & 1245 \\
\hline \multirow[t]{4}{*}{ Clearnose } & 2000 & 186 & 207 & 46 & 61 & - & - & 25 & 40 & 257 & 308 \\
\hline & 2001 & 136 & 154 & 41 & 27 & - & - & 104 & 79 & 281 & 260 \\
\hline & 2002 & 93 & 85 & 23 & 12 & - & - & - & - & 116 & 97 \\
\hline & Total & 415 & 446 & 110 & 100 & - & - & 129 & 119 & 654 & 665 \\
\hline \multirow[t]{4}{*}{ Rosette } & 2000 & 89 & 84 & 4 & 7 & 9 & 1 & 5 & 2 & 107 & 94 \\
\hline & 2001 & 118 & 153 & 11 & 7 & 13 & 5 & 8 & 14 & 150 & 179 \\
\hline & 2002 & 53 & 50 & 1 & 2 & - & - & - & - & 54 & 52 \\
\hline & Total & 260 & 287 & 16 & 16 & 22 & 6 & 13 & 16 & 311 & 325 \\
\hline \multirow[t]{4}{*}{ Little } & 2000 & 80 & 241 & 361 & 409 & 309 & 312 & 109 & 153 & 1059 & 1115 \\
\hline & 2001 & 36 & 312 & 288 & 320 & 262 & 402 & 144 & 224 & 1030 & 1258 \\
\hline & 2002 & 28 & 160 & 246 & 249 & - & - & - & - & 374 & 409 \\
\hline & Total & 44 & 713 & 895 & 978 & 571 & 714 & 253 & 377 & 2463 & 2782 \\
\hline \multirow[t]{4}{*}{ Smooth } & 2000 & - & 3 & 9 & 10 & 6 & 5 & 29 & 20 & 44 & 38 \\
\hline & 2001 & 2 & 8 & 72 & 85 & 11 & 8 & 38 & 29 & 123 & 130 \\
\hline & 2002 & - & 2 & 36 & 31 & - & - & - & - & 36 & 33 \\
\hline & Total & 2 & 13 & 117 & 126 & 17 & 13 & 67 & 49 & 203 & 201 \\
\hline \multirow[t]{4}{*}{ Thorny } & 2000 & 2 & - & 22 & 22 & 3 & 2 & 34 & 30 & 61 & 54 \\
\hline & 2001 & 2 & 2 & 87 & 101 & 3 & 10 & 26 & 30 & 118 & 143 \\
\hline & 2002 & 1 & - & 28 & 28 & - & - & - & - & 29 & 28 \\
\hline & Total & 5 & 2 & 137 & 151 & 6 & 12 & 60 & 60 & 208 & 225 \\
\hline
\end{tabular}

ovarian development should provide a better metric for size at maturity. However, at this time, there is no way of staging female maturity without sacrificing the animal.

There may be a distinction between morphometric maturity and functional maturity. In some crab species, female morphometric maturity occurs before functional or ovarian maturity (Fernandez-Vergaz et al., 2000). This means that morphometric maturity will underestimate the size at maturity. This is probably true for male skates. To determine size at maturity, testis development and sperm production should be shown to confirm maturity (Pratt and Otake, 1990). In female skates, however, the opposite may be true. Since the length of the cloaca probably changes after copulation or egg deposition, ovarian maturity may occur before morphometric maturity.
The regression technique discussed here works well when there is a change in slope at a particular inflection point. However, if there is overlap between sizes of mature and immature animals, it may not work as well (Somerton, 1980). Some of the male skate, particular in thorny skates, do exhibit this overlap. Thorny skates appear to mature over a very wide length interval. The minimum size at maturity may be $50 \mathrm{~cm}$, but many do not appear to mature until a much larger size (Fig. $5 \mathrm{~g}$ ). This results in a second minimum appearing at a larger size. Somerton (1980) has a second method that may be useful for the future.

This technique appears to provide insights into size at maturity when no other data exist. However, the technique needs to be validated with more traditional 

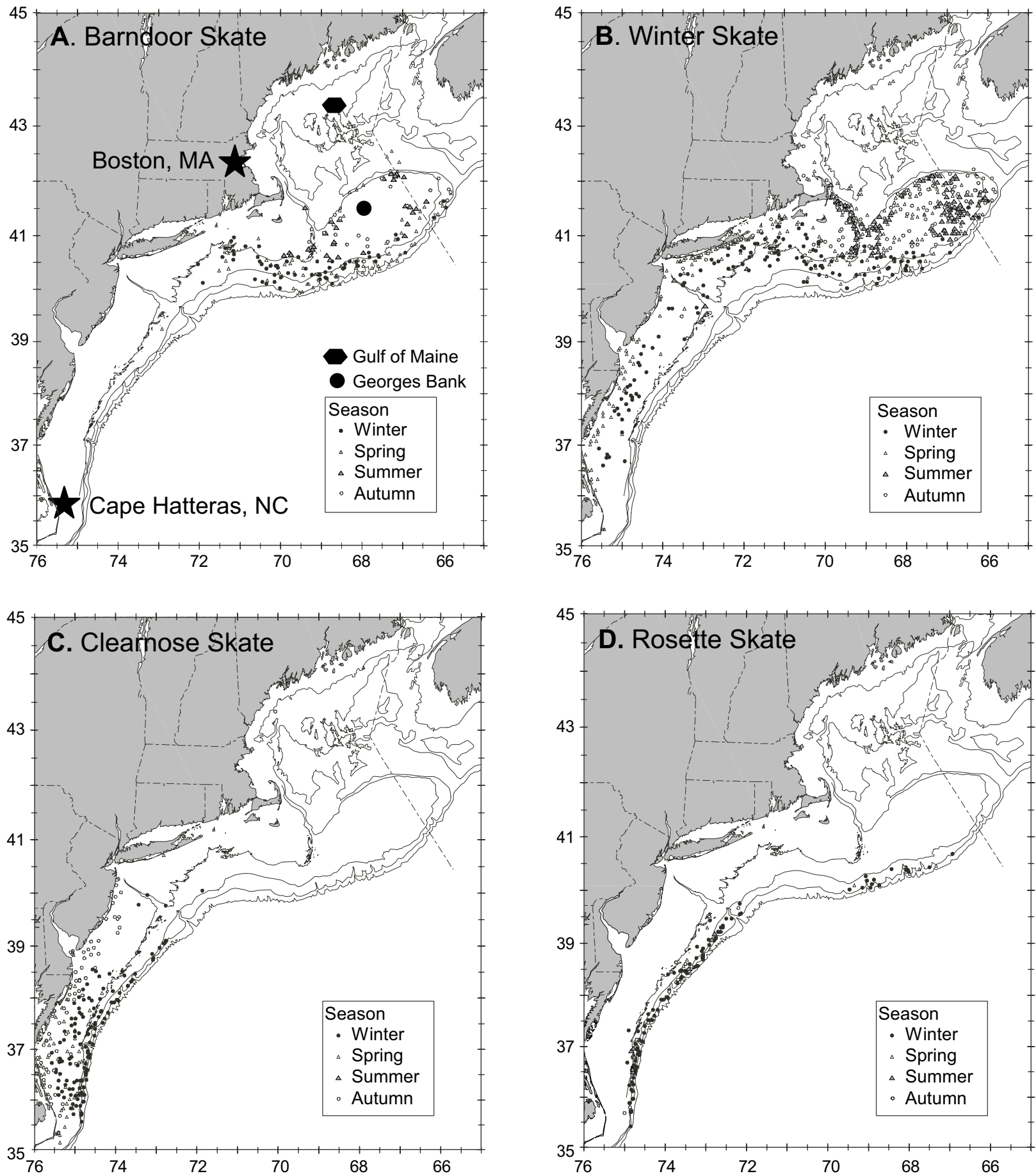

Fig. 4. Location of skates sampled during 2000-2002 by season, all years combined.

methods such as determination of ovarian development and sperm production. If this technique can be validated, then it will be useful for species whose populations have been determined to be declining.

\section{Acknowledgements}

The author thanks S. Cadrin who provided valuable guidance in the analyses. The author is also indebted to 

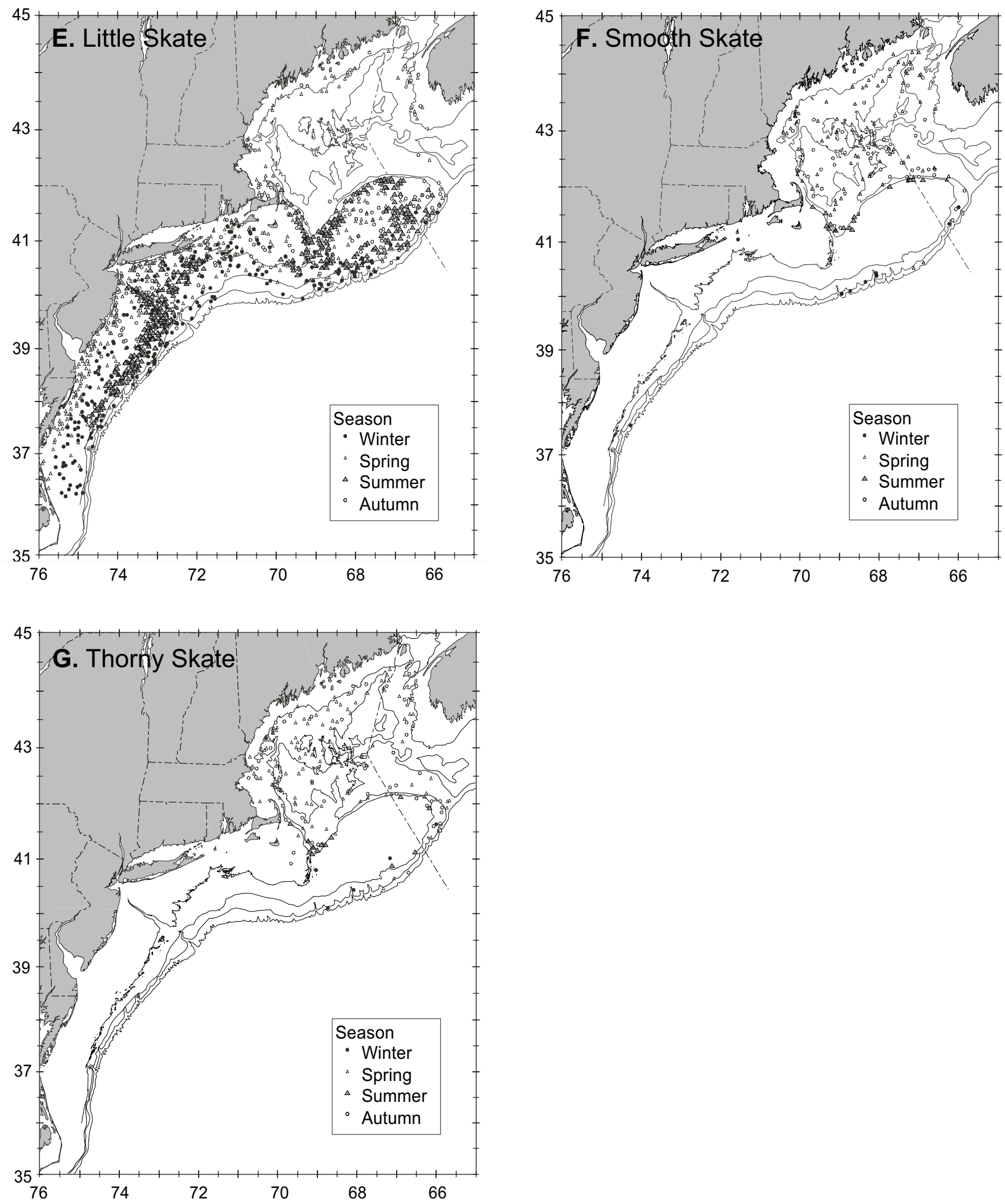

Fig. 4. (Cont'd). Location of skates sampled during 2000-02 by season, all years combined. 

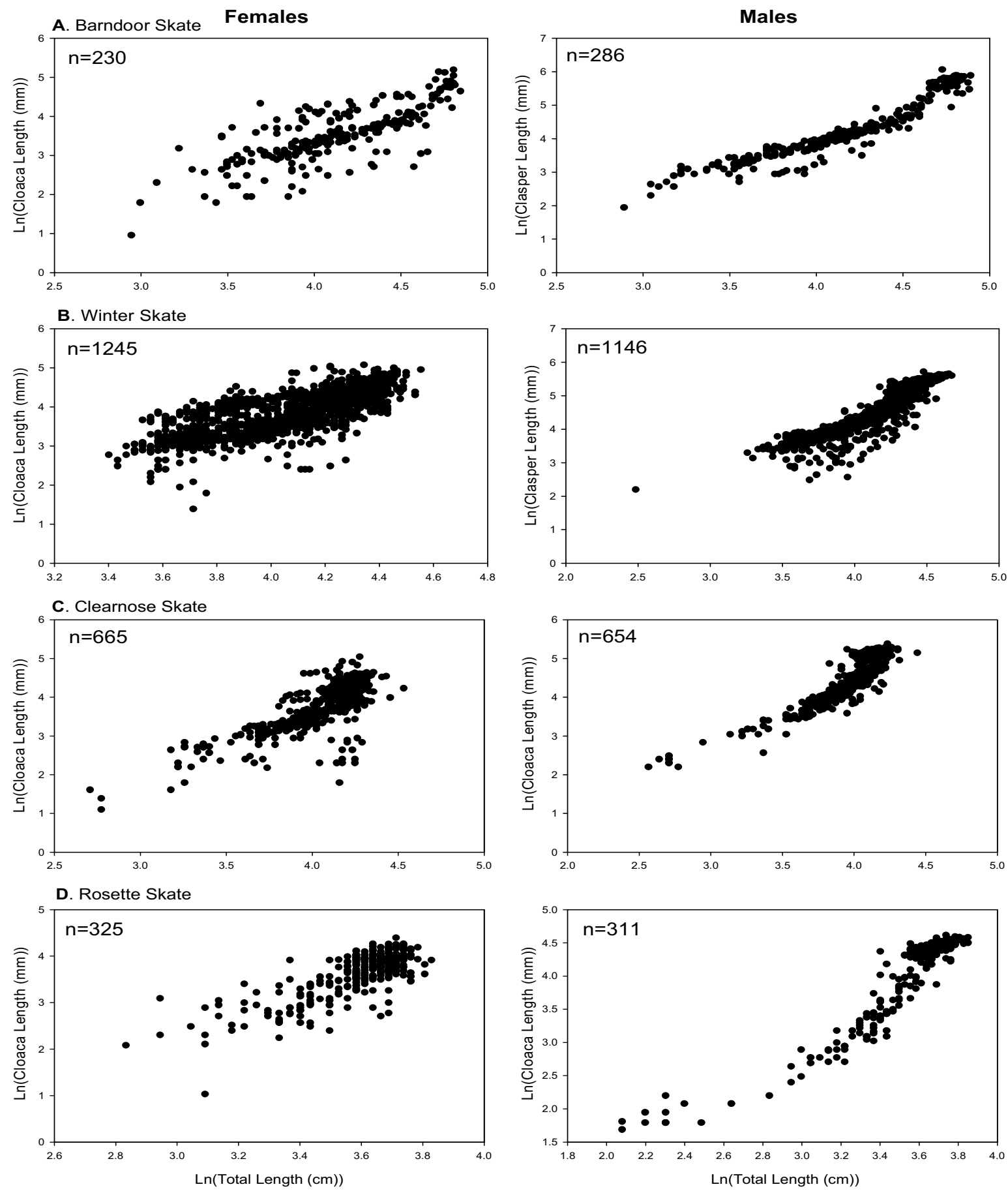

Fig. 5. Clasper length or cloaca length (natural logarithm scale) plotted against total length (natural logarithm scale). 

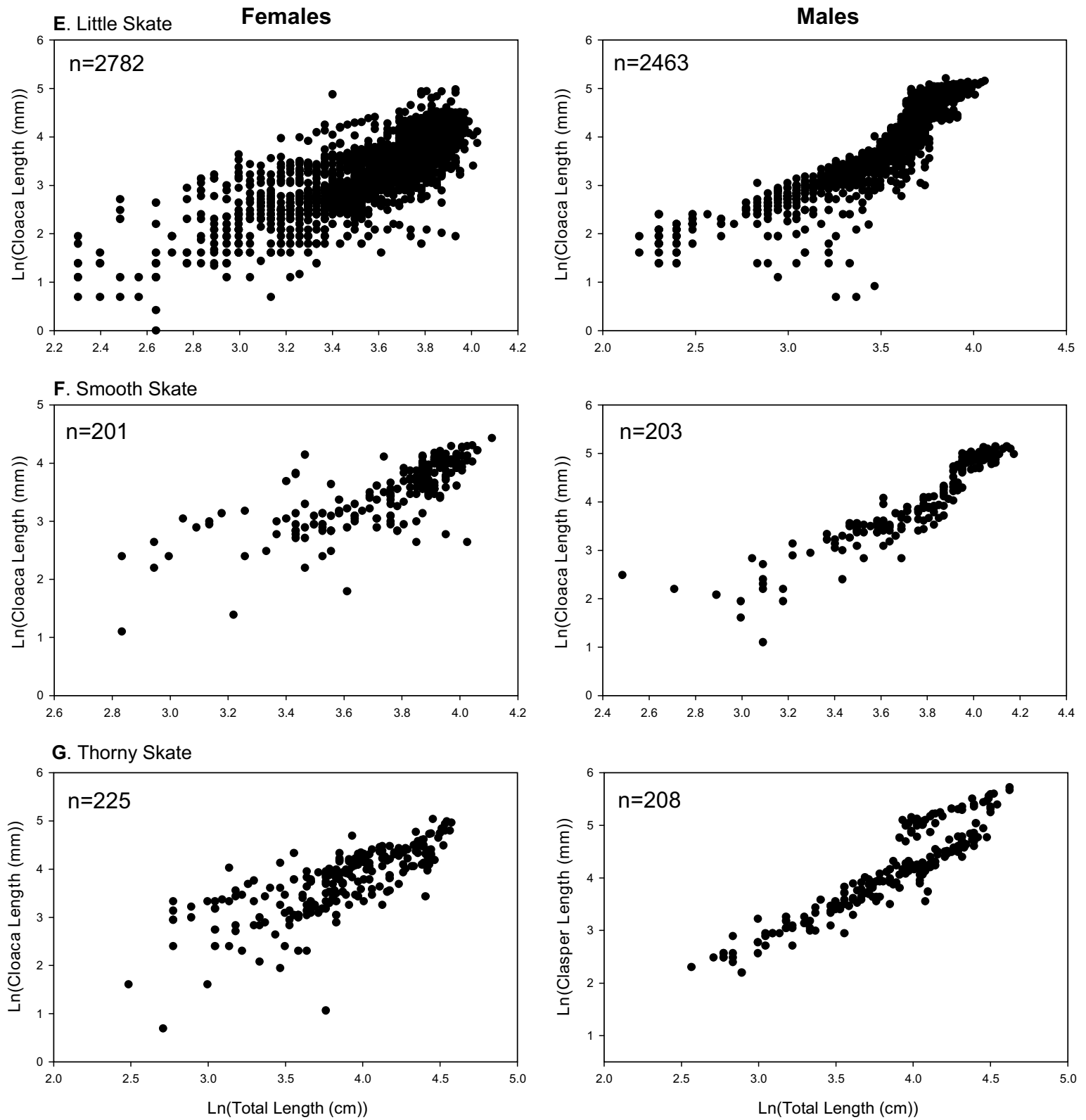

Fig. 5. Clasper length or cloaca length (natural logarithm scale) plotted against total length (natural logarithm scale).

TABLE 2. Size at first maturity $(\mathrm{cm})$ by sex for seven skate species.

\begin{tabular}{lrl}
\hline \hline Species & Males & Females \\
\hline Barndoor & $\mathbf{1 0 0}$ & $\mathbf{9 6 - 1 0 5}$ \\
Winter & $53-58$ & $66-73$ \\
Clearnose & 56 & $59-65$ \\
Rosette & 33 & $33-35$ \\
Little & 39 & $40-42$ \\
Smooth & 50 & $33-48$ \\
Thorny & 50 & $43-46$ \\
\hline
\end{tabular}



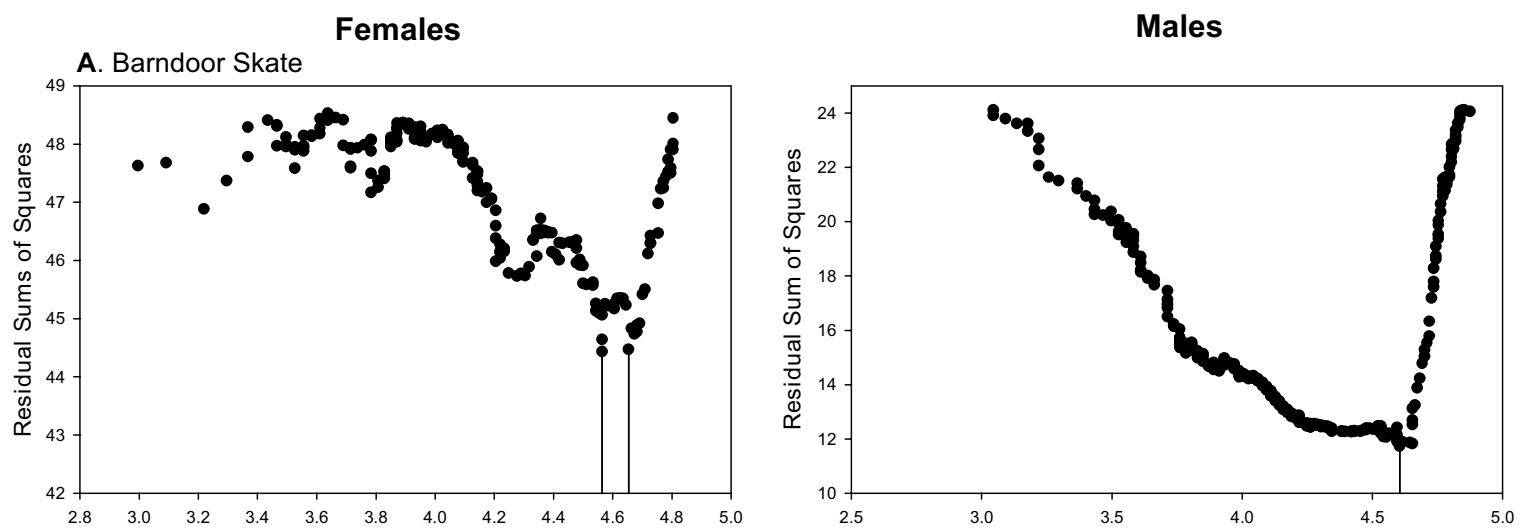

B. Winter Skate
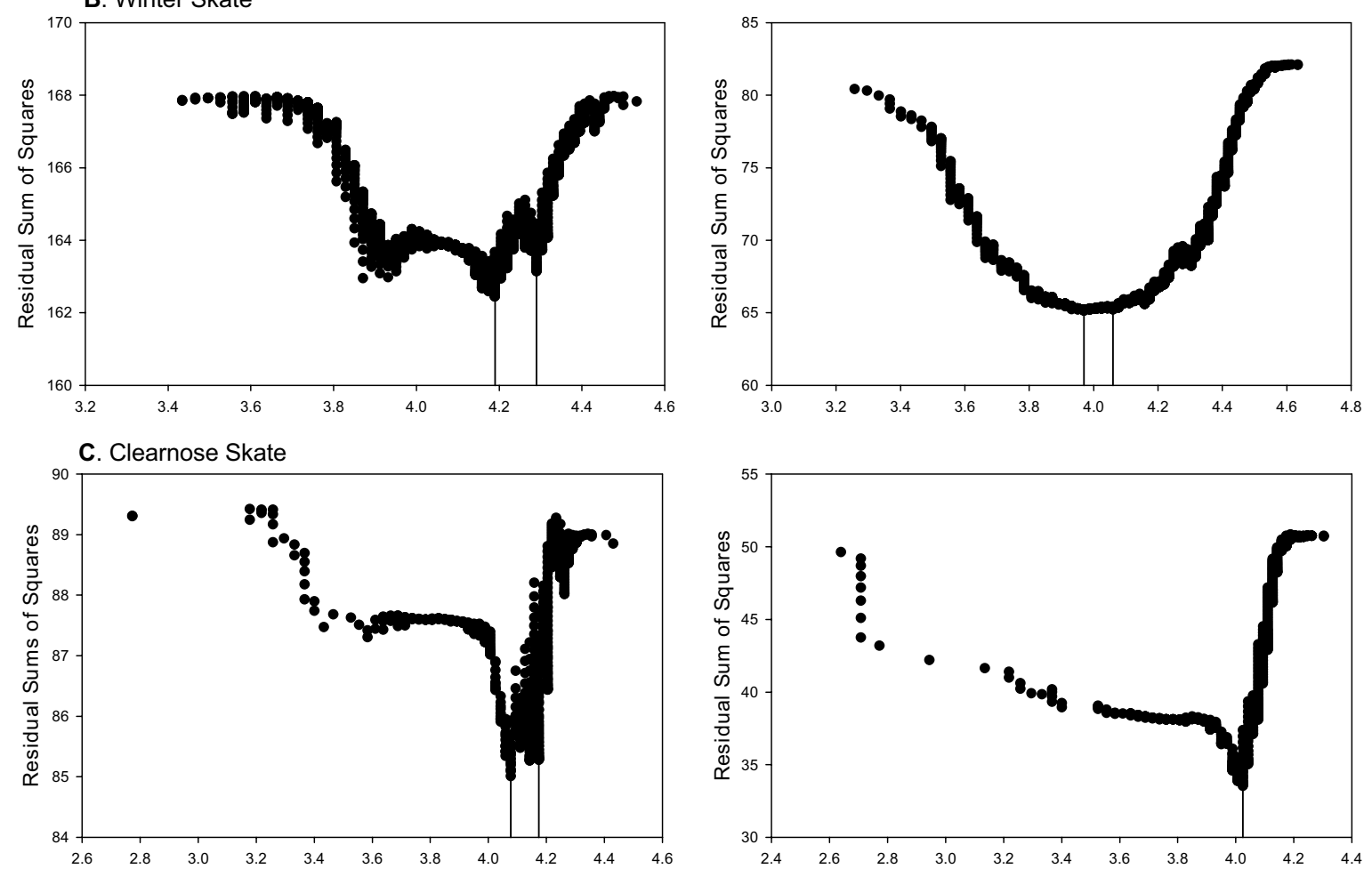

D. Rosette Skate
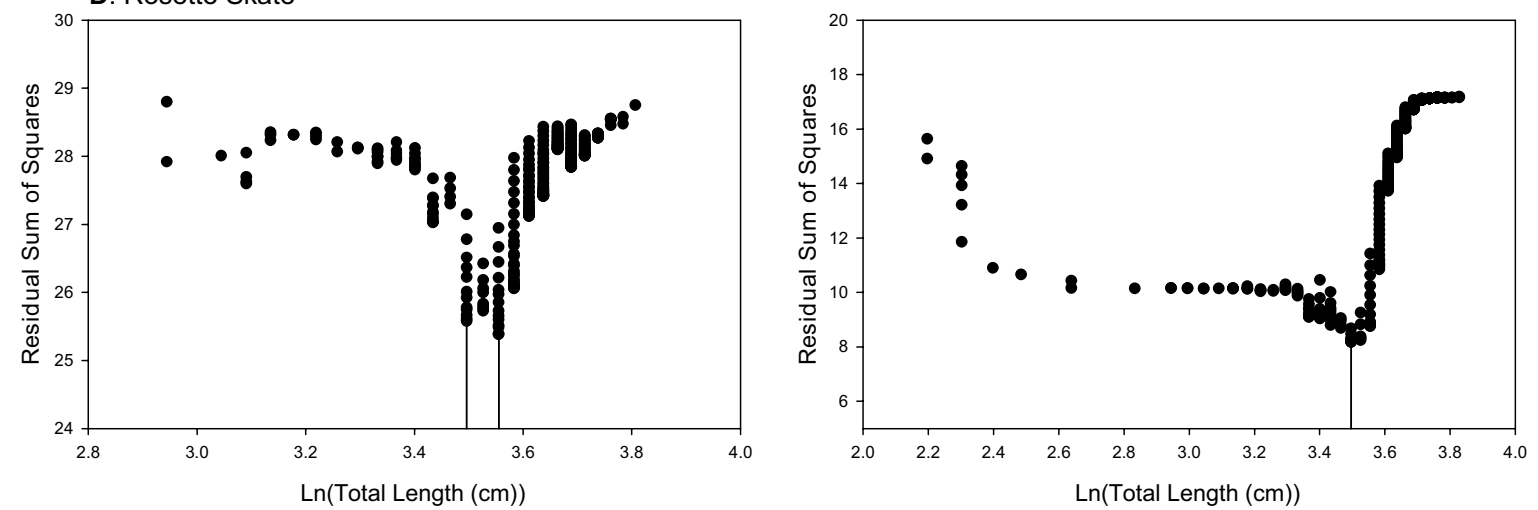

Fig. 6. Residual sum of squares plotted against total length (natural logarithm scale). The dropped lines show the location of the size at first maturity or interval for the size at first maturity. 

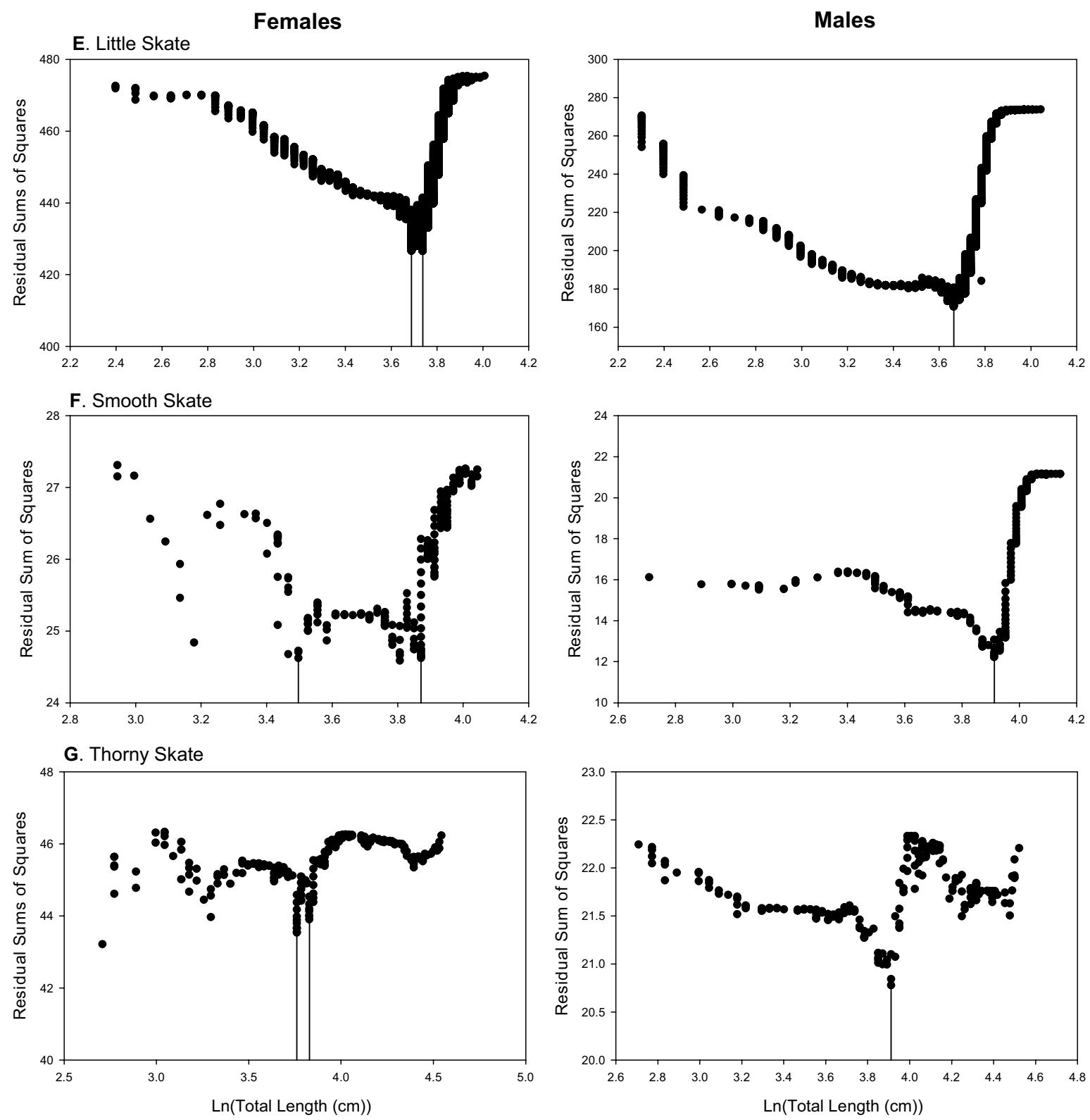

Fig. 6. (Cont'd). Residual sum of squares plotted against total length (natural logarithm scale). The dropped lines show the location of the size at first maturity or interval for the size at first maturity.

the many scientists and crew of the Albatross $I V$ who participated in the research cruises to collect the data.

\section{References}

AZAROVITZ, T. R. 1981. A brief historical review of the Woods Hole Laboratory trawl survey time series. In: Bottom trawl surveys. W. G. Doubleday, and D. Rivard (eds.). Can. Spec. Publ. Fish. Aquat. Sci., 58: 62-67.

CASEY, J. M., and R. M. MYERS. 1998. Near extinction of a large widely distributed fish. Science, 281: 690-692.
DAIBER, F. C. 1960. A technique for age determination in the skate, Raja eglanteria. Copeia, 3: 258-260.

DEL RIO, J. L., and S. JUNQUERA. MS 2000. Seasonality and reproductive parameters of the thorny skate (Raja radiata Donovan, 1808) in NAFO Division 3N. NAFO SCR Doc., No. 18, Serial No. N4247, 8 p.

FERNANDEZ-VERGAZ, V., L. J. LOPEZ ABELLAN, and E. BALGUERIAS. 2000. Morphometric, functional and sexual maturity of the deep-sea red crab Chaceon affinis inhabiting Canary Island waters: chronology of maturation. Mar. Ecol. Prog. Ser., 204: 169-178.

FITZ, E. S. 1956. An introduction to the biology of Raja 
eglanteria Bosc 1802 and Raja erinacea Mitchell 1825 as they occur in Delaware Bay. MA Thesis, University of Delaware, Newark, DE, 91 p.

FITZ, E. S., and F. C. DAIBER. 1963. An introduction to the biology of Raja eglanteria Bosc 1802 and Raja erinacea Mitchell 1825 as they occur in Delaware Bay. Bull Bingham Oceanogr. Coll., 18(3): 69-97.

FRISK, M. G., T. J. MILLER, and M. J. FOGARTY. 2001. Estimation and analysis of biological parameters in elasmobranch fishes: a comparative life history study. Can. J. Fish. Aquat. Sci., 58: 969-981.

GELSLEICHTER, J. J. 1998. Vertebral cartilage of the clearnose skate, Raja eglanteria: development, structure, ageing, and hormonal regulation of growth. Dissertation, The College of William and Mary, VA.

JOHNSON. G. F. 1979. The biology of the little skate, Raja erinacea Mitchill 1825, in Block Island Sound, Rhode Island. University of Rhode Island.

MCEACHRAN, J. D. 2002. Skates. Family Rajidae. In: Bigelow and Schroeder's fishes of the Gulf of Maine. $3^{\text {rd }}$ Edition. B. B. Collette and G. Klein-MacPhee (eds.). p. 60-75. Smithsonian Institution Press, Washington D.C., 748 p.

MCEACHRAN, J. D., and J. A. MUSICK. 1975. Distribution and relative abundance of seven species of skates (Pisces: Rajidae) which occur between Nova Scotia and Cape Hatteras. Fish. Bull. (U.S.), 73: 110-136.

NEFSC. 2000. Report of the 30th Northeast Regional Stock Assessment Workshop: Stock Assessment Review Committee (SARC) Consensus Summary of Assessments. NOAA/NMFS/NEFSC: Woods Hole, MA. NEFSC Ref. Doc., No. 00-04.
Report of the 34th Northeast Regional Stock Assessment Workshop: Stock Assessment Review Committee (SARC) Consensus Summary of Assessments. NOAA/NMFS/NEFSC: Woods Hole, MA. NEFSC Ref. Doc., No. 02-07.

PRATT, H. L., and T. OTAKE. 1990. Recommendations for work needed to increase our knowledge of reproduction relative to fishery management. In: Elasmobranchs as Living Resources: Advances in the Biology, Ecology, Systematics, and the Status of the Fisheries. H. L. Pratt, S. H. Gruber, and T. Taniuchi (eds.). p. 509-510. NOAA Tech. Rep., No. NMFS 90, 518 p.

SIMON, J. E., and K. T. FRANK. MS 1996. Assessment of the division $4 \mathrm{VsW}$ skate fishery. DFO Atl. Fish. Res. Doc., No. $105,51 \mathrm{p}$.

SOMERTON, D. A. 1980. A computer technique for estimating the size of sexual maturity in crabs. Can. J. Fish. Aquat. Sci., 37: 1488-1494.

STEVEN, G. A. 1934. Observations on the growth of the claspers and cloaca in Raia clavata Linnaeus. J. Mar. Biol. Ass. U.K., 19(2): 887-899.

TEMPLEMAN, W. 1982. Development, occurrence, and characteristics of egg capsules of the thorny skate, Raja radiata, in the Northwest Atlantic. J. Northw. Atl. Fish. Sci., 3(1): 47-56.

1984. Migrations of thorny skate, Raja radiata, tagged in the Newfoundland area. J. Northw. Atl. Fish. Sci., 5: 55-63.

WARING, G.T. 1984. Age, growth, and mortality of the little skate off the Northeast coast of the United States. Trans. Am. Fish. Soc., 113: 314-321. 
